\title{
The economic impact of obesity in the United States
}

This article was published in the following Dove Press journal:

Diabetes, Metabolic Syndrome and Obesity:Targets and Therapy

17 August 2010

Number of times this article has been viewed

\section{Ross A Hammond \\ Ruth Levine \\ Economic Studies Program, Brookings Institution, Washington DC, USA}

Correspondence: Ross A Hammond Brookings Institution, 1775 Massachusetts Ave NW, Washington DC 20036, USA

Tel +l 2027976000

Email rhammond@brookings.edu
Abstract: Over the past several decades, obesity has grown into a major global epidemic. In the United States (US), more than two-thirds of adults are now overweight and one-third is obese. In this article, we provide an overview of the state of research on the likely economic impact of the US obesity epidemic at the national level. Research to date has identified at least four major categories of economic impact linked with the obesity epidemic: direct medical costs, productivity costs, transportation costs, and human capital costs. We review current evidence on each set of costs in turn, and identify important gaps for future research and potential trends in future economic impacts of obesity. Although more comprehensive analysis of costs is needed, substantial economic impacts of obesity are identified in all four categories by existing research. The magnitude of potential economic impact underscores the importance of the obesity epidemic as a focus for policy and a topic for future research.

Keywords: obesity, economic impact, United States, economic cost

\section{Introduction}

Over the past several decades, obesity has grown into a major global epidemic. By 2002, nearly 500 million people were overweight worldwide. In the United States (US), rates of obesity have doubled since 1970 to over $30 \%$, with more than two-thirds of Americans now overweight. ${ }^{1}$ The determinants of this epidemic are likely complex, ${ }^{2,3}$ with substantial heterogeneity at the individual level in both causes and consequences that is beyond the scope of the current review.

In this article, we provide an overview of the state of research on the likely economic impact of the US obesity epidemic at the aggregate level. We conducted a broad search of the literature that addresses potential economic costs of obesity. The most recent studies that sample US populations have identified at least four major categories of economic impact linked with the obesity epidemic: direct medical costs, productivity costs, transportation costs, and human capital costs. We systematically review current evidence on each set of costs in turn, and discuss important gaps for future research along with potential trends in future economic impacts of obesity. This review adds to the current research on the economic impact of obesity by providing a more comprehensive overview of the range of effects, as well as a summary of the most up-to-date estimates.

\section{Direct medical costs}

One of the most cited economic impacts of the obesity epidemic is on direct medical spending. Obesity is linked with higher risk for several serious health conditions, 
such as hypertension, type 2 diabetes, hypercholesterolemia, coronary heart disease (CHD), stroke, asthma, and arthritis. Direct medical spending on diagnosis and treatment of these conditions, therefore, is likely to increase with rising obesity levels. Several studies offer retrospective or prospective estimates of the degree of disease incidence that can be linked to obesity, and of the magnitude of associated direct medical costs.

\section{Incidence of diseases associated with obesity}

The most common definitions of obesity are based on body mass index (BMI), defined as weight in kilograms divided by height in meters squared. Obesity in adults is generally defined as a BMI of 30.0 or greater, with BMI of 25.0-29.9 categorized as overweight. ${ }^{4}$

Thompson et $\mathrm{al}^{5}$ present a dynamic model of the relationships between BMI and the risks of five diseases linked with obesity: hypertension, hypercholesterolemia, type 2 diabetes mellitus, CHD, and stroke. The model captures both direct and indirect effects of obesity on health outcomes - obesity is a risk factor for hypertension, hypercholesterolemia, and diabetes, which are themselves risk factors for CHD and stroke. Estimated using a variety of data sources (including the National Health And Nutritional Examination Survey or NHANES, and the Framingham Study), the model gives future risks of all five diseases, life expectancy, and lifetime medical costs associated with the five diseases for men and women aged 35 to 64 years in each of four representative BMI groups ("healthy" BMI of 22.5, "overweight" BMI of 27.5, "obese" BMI of 32.5, and "severely obese" BMI of 37.5). BMI is assumed to be constant at its initial value for all individuals, with other risk factors adjusted for each year of aging. Results from the model demonstrate substantial increases in disease risk with increasing BMI. Relative to the group with BMI of 22.5 , risk of hypertension is $40 \%-60 \%$ higher in the overweight (BMI 27.5), and twofold higher in the obese (BMI 32.5). Lifetime risk of CHD is $41.8 \%$ in obese men compared to $34.9 \%$ in the nonobese; for women, risk increases from $25 \%$ for the nonobese to $32.4 \%$ for the obese.

Similar relative disease risk rates for the overweight and obese are found in large-scale population studies. The Health Professionals Follow-up Study, based on 29,000 men observed over a three year time-period, found CHD risk to be 50\% higher in the overweight (BMI 25-28.9), twice as high in the obese (BMI 29-32.9), and three times as high in the severely obese $(\mathrm{BMI}>33)$, compared to healthy weight men $(\mathrm{BMI}<23) .{ }^{6}$ For women, analysis ${ }^{7}$ based on the Nurses
Health $\mathrm{Study}^{8}$ found the relative risk of type 2 diabetes to be 40.3 for women with BMIs between 31 and 32.9 (compared to those with BMI of less than 22). Analysis of NHANES-II cross-sectional data for both men and women found risk of hypertension and diabetes to be increased 3.0 times and 2.9 times, respectively, compared to the nonoverweight. ${ }^{9,10}$ A large-scale telephone survey of 195,000 adults ${ }^{11}$ found the odds ratio for the overweight and obese (compared to normal weight) to be 1.59 and 3.44, respectively for diabetes, 1.82 and 3.50, respectively for high blood pressure, and 1.50 and 1.91, respectively for high cholesterol. Statistically significant effects for asthma and arthritis were also found. A different study quantified an increase of $1 \mathrm{mmHg}$ in systolic blood pressure resulting from each one-unit increase in BMI among healthy 20-29 year olds. ${ }^{12}$

\section{Medical costs associated with incidence of obesity-related diseases}

Associated with incidence of obesity-related diseases are direct medical costs for diagnosis and treatment of these conditions. Numerous studies estimate these costs, using a variety of methodologies including: cohort studies, case studies, dynamic models, nationwide representative surveys, regression analyses, and simulation forecasting. There is widespread agreement across this literature that the medical costs associated with obesity are substantial; however, there are important differences between the studies.

Two recent studies use cohorts drawn from managed care organizations to estimate relative costs for the obese and overweight compared to the nonoverweight. This approach allows for direct study of individual medical histories (and charged costs) with no aggregation, but relies on self-report for BMI and other initial data. Cohorts examined may not be nationally representative. Thompson et $\mathrm{al}^{13}$ base their estimates on a retrospective study conducted at Kaiser Permanente in Oregon, with 1,286 subjects who responded to a 1990 random sample survey. Respondents were between 35 and 64 years old, had self-reported BMIs greater than 20, were nonsmokers, and had no history of heart disease. Thompson et al sorted subjects into three categories - healthy, overweight, and obese - according to initial (1990) BMI. They followed each group over a nine year period, using electronic records and local retail prices to tally real costs for all inpatient care, outpatient services, and prescriptions. Results show significantly higher accumulated costs for the obese and overweight than for the healthy-weight group. The obese (BMI $\geq 30$ ) had $36 \%$ higher average annual health care costs than the healthy-weight group, including $105 \%$ 
higher prescription costs and 39\% higher primary-care costs. The overweight (BMI 25-29) had 37\% higher prescription costs and $13 \%$ higher primary-care costs than the healthyweight group.

Wolf ${ }^{14}$ and Pronk et al ${ }^{15}$ studied health care costs among a stratified random sample $(n=5,689)$ drawn from members of a managed care organization in Minnesota aged 40 and older. They compare total medical care charges over an 18-month period across BMI categories, controlling for age, race, sex, and chronic disease status. Results show that a one-unit increase in BMI translates to a $1.9 \%$ increase in median medical spending during the study period.

Several studies use dynamic models to estimate medical care costs associated with overweight and obesity over a substantial time period. Using a dynamic multi-stage model of the relationship between BMI and risk for five diseases strongly linked to weight status (see above), Thompson et a ${ }^{13}$ generate associated medical care costs for each stage of the model. They find overweight (BMI 27.5) to increase expected lifetime medical care costs for the five diseases studied by almost $20 \%$ compared to the healthy-weight group (BMI 22.5). Obesity increases lifetime medical care costs for these diseases by $50 \%$ above baseline, and severe obesity can almost double them.

Gorsky et $\mathrm{al}^{9}$ construct three "hypothetical" cohorts of 10,000 women each - one cohort with healthy weight, one overweight, and one obese. They begin each cohort at age 40 years and extrapolate into the future through age 65 years, conducting incidence-based analysis of the excess costs associated with remaining overweight or obese over this time period. Results show that the obese cohort would incur excess costs of \$53 million (with 3\% annual discounting) over the 25 years, and the overweight cohort would incur excess costs of $\$ 22$ million. Applying these results to the broader US population, the authors estimate that approximately \$16 billion will be spent between 1996 and 2021 on treatment of health conditions associated with overweight and obesity in middle-aged American women.

Regression analysis based on nationally representative surveys is another widely-used approach in the literature on health care costs associated with obesity. Finkelstein et al ${ }^{16}$ use data from the 1998 and 2006 Medical Expenditure Panel Surveys (MEPS) along with National Health Expenditure Accounts data on health spending to construct a regression that controls for demography, smoking status, and insurance status. They divide cost estimates among payers (Medicare, Medicaid, or private) and cost category (inpatient, outpatient, or prescription). Estimated medical costs of obesity are as high as $\$ 147$ billion a year for 2008 , or almost $10 \%$ of all medical spending. This is a substantial increase from their 1998 estimate of $\$ 78.5$ billion a year. The authors attribute the majority of this increase to higher prevalence of overweight. Private payers bear the majority of estimated costs, although public-sector spending is also substantial - Medicare spending would be an estimated $8.5 \%$ lower and Medicaid spending $11.8 \%$ lower in the absence of obesity. Across all payers, comparison of the obese to healthy-weight individuals shows 2006 medical spending that is $41.5 \%$ higher as a result of obesity.

Rather than providing a point-estimate of obesity's impact on spending, Thorpe et $\mathrm{al}^{17}$ focus on assessing the link between increases in obesity prevalence and increases in spending over time. They use self-reported data on both medical conditions and BMI from two nationally representative surveys (the National Medical Expenditure survey and the Household Component of the MEPS), and construct a two-part regression controlling for key individual variables (such as demography, smoking, and insurance status). The regression estimates the "obesity-attributable" portion of per-capita health care spending increases between 1987 and 2001 to be $27 \%$ (adjusted for inflation), with $12 \%$ due solely to increases in prevalence of obesity. Most of this increase was found to be due to spending on diabetes or hypertension specifically. At the beginning of the study period in 1987, per capita health care spending was estimated to be $15.2 \%$ higher for the obese than for healthy-weight individuals. By 2001, this gap had grown to $37 \%$. The rate of growth in spending among the obese group was much higher than overall per capita spending growth.

Allison et $\mathrm{al}^{18}$ examine whether any of the direct medical costs of obesity estimated in previous studies might be offset by increased (early) mortality associated with obesity. They conclude that increased mortality may lower costs somewhat, though inclusion of this factor does not affect the qualitative conclusion that such costs are likely substantial.

Obesity-related medical costs occur not only in adult populations, but in children as well. The annual direct costs of childhood obesity in the US are estimated at about $\$ 14.3$ billion. ${ }^{19,20}$ In addition to these immediate costs, current childhood obesity implies future direct costs given that overweight children and adolescents may become obese adults. ${ }^{21}$ Lightwood et al ${ }^{22}$ estimate the likely future economic burden that will result from current high rates of overweight in US adolescents. They simulate the costs of excess obesity (and associated diseases) among US adults aged 35 to 64 years from 2020 to 2050 . Results suggest that currently 
existing levels of adolescent overweight will result in close to $\$ 45$ billion in direct medical costs over this period, affecting young as well as middle-aged adults. The authors argue that these costs may be unavoidable, with currently existing technologies unable to reduce significantly the likely future consequences of current adolescent overweight.

A pair of recent studies examines who ultimately bears the health care costs associated with obesity. Bhattacharya and Bundorf ${ }^{23}$ use data from the National Longitudinal Survey of Youth (NLSY), collected by the Bureau of Labor Statistics (BLS), to capture worker wage information and the MEPS to capture medical expenditure information. Their regression analysis concludes that many of the health care costs associated with obesity "are passed on to obese workers with employer-sponsored health insurance in the form of lower cash wages". The authors argue that this gap in health-insurance premiums may explain most of the wage gap usually attributed to discrimination.

Dall et $\mathrm{al}^{24}$ focus specifically on diabetes, estimating that the US national economic burden of pre-diabetes and diabetes was $\$ 153$ billion in higher medical costs for the year 2007 alone, with an average annual medical cost per case of $\$ 1,744$ for undiagnosed diabetes, $\$ 6,649$ for diagnosed diabetes, and $\$ 443$ for pre-diabetes. Although this study does not estimate the fraction of these diabetes costs that are attributable to obesity, other evidence suggests it may be substantial (see above). Dall et al argue that the costs of diabetes are borne by all Americans, not only those with diabetes, and amount to a per-person cost of around $\$ 700$ a year.

\section{Productivity costs}

In addition to direct medical costs of obesity, a number of more indirect costs are part of the overall economic impact of obesity. Of these, effects on productivity play the largest role empirically. The productivity costs of obesity have been well-documented in a variety of studies, with widespread consensus that such costs are substantial, but with important differences in magnitude between the individual estimates.

The literature in this area includes analyses of the aggregate productivity loss due to obesity, as well as estimates for several distinct sub-categories of productivity costs. Many of these categories relate to productivity loss originating in the labor market, including 'absenteeism' (first-order productivity costs due to employees being absent from work for obesity-related health reasons) and 'presenteeism' (decreased productivity of employees while at work). Other categories of productivity costs that have been analyzed thus far include: premature mortality and loss of quality-adjusted life years
(QALYs); higher rates of disability benefit payments; and welfare loss in the health insurance market.

\section{Absenteeism}

Due to relative ease of measurement, studies estimating the absenteeism costs of overweight and obesity make up the largest category of productivity cost studies to date. Methodologies vary, though the studies consistently find strong correlation between obesity and higher rates of absenteeism. Rather than giving an exhaustive review of absenteeism studies, we summarize here key findings and methodological differences across several recent papers that have addressed the relationship between obesity and absenteeism and the associated costs.

Studies vary by the measures used to identify obesity the most common is BMI, but several studies use weight directly (and control for height in regression analysis). Generally, studies allow for a nonlinear relationship when modeling the effects of weight on absenteeism by dividing BMI into categories such as under-weight, normal weight, overweight, and obese. BMI is most often derived from data based on self-reported height and weight. Some studies correct for potential bias (under- or over- reporting) in data of this kind using correlations between self-reported weight and height and objectively observed values from NHANES. The outcome variables used also vary in definition across studies. Certain authors, such as Burton et $\mathrm{al}^{25}$ use only longer periods of health-related work absence, defined as short-term disability, while others use either paid time off for sick leave or self-reported absence due to illness.

In order to identify a causal relationship between obesity and absenteeism, authors control for a list of observables that also affect absenteeism; some authors employ econometric models other than standard ordinary least squares (OLS) regressions in order to control for endogeneity of weight in determining work absence. Covariates generally include demographic variables, years of education, income, occupation, smoking or alcohol consumption, and various other health risks or conditions. Frone ${ }^{26}$ runs two sets of regressions, the first of which excludes nonweight - related physical and mental health conditions, in order to test whether the addition of those conditions mediates the effect of obesity on absenteeism; he finds that it does.

The result most consistently identified across the studies is a positive and statistically significant correlation between obesity and measures of absenteeism, even after controlling for the covariates discussed above. Because of the differences in methodologies, the magnitudes of the parameter 
estimates on obesity are not widely comparable. For example, Tsai et $\mathrm{al}^{27}$ find that in the North American division of Shell Oil Company, 3.73 additional days of work were lost per year for each obese employee relative to their normal-weight co-workers, while Serxner et $\mathrm{a}^{28}$ report that employees considered at risk for obesity were 1.23 times more likely to be in the 'high-absenteeism' group than those who were not. Durden et $\mathrm{al}^{29}$ show that obese workers were $194 \%$ more likely to use paid time off than their counterparts.

A subset of the authors discussing absenteeism translates their results on the correlation between obesity and absenteeism into dollar amounts representing the cost of the estimated productivity loss. This is usually done by calculating the level of compensation for the relevant workers either from survey data or BLS averages. Tsai et $\mathrm{al}^{27}$ find that the productivity losses to Shell Oil Company alone due to absenteeism effects of obesity were worth $\$ 11.2$ million per year. This amount includes only the direct productivity costs of absenteeism (that the employee is paid while not at work); it does not account for any secondary effects on training, morale, or other network effects. Trogdon et $\mathrm{al}^{30}$ provide a range of estimates for nationwide annual productivity losses due to obesityrelated absenteeism of between $\$ 3.38$ billion ( $\$ 79$ per obese individual) and $\$ 6.38$ billion ( $\$ 132$ per obese individual).

\section{Presenteeism}

Obesity could also contribute to productivity loss if obese individuals are less productive while present at the workplace. This may occur as a result of physical and mental health conditions that are more common among obese workers and negatively affect productive ability. Alternatively, a common outside factor may make individuals more likely to both be obese and relatively less productive. The studies reviewed here focus primarily on the magnitude of the presenteeism effect, rather than the mechanism of action.

Studies by Ricci and $\mathrm{Chee}^{31}$ and Pronk et $\mathrm{al}^{15}$ both include measures of presenteeism in addition to absenteeism. Ricci and Chee use the Caremark American Productivity Audit, a phone interview that included several questions regarding health-related reduced work performance. Respondents were asked to estimate the average amount of time elapsed between arriving and starting work on days when they were not feeling well, as well as total hours of lost concentration, repeating a job, or feeling fatigued. The authors then look at total lost productive time (LPT) (the sum of absenteeism and presenteeism), and measure the effects of obesity controlling for a list of covariates. In a second stage, the authors add a variable for the number of co-occurring health conditions to test whether the effects of obesity are mediated by overall health status. Finally, they convert LPT into dollars using workers' self-reported wages.

Ricci and Chee find that obese workers are more likely to have positive LPT than their counterparts, and on average have more of it. As also found by Frone, ${ }^{26}$ this effect appears to be largely driven by the higher propensity of obese workers to have co-occurring conditions. The monetary value of the cost of excess LPT among obese workers is estimated at $\$ 11.7$ billion per year. Of the total cost of LPT, two-thirds is attributable to presenteeism and one-third to absenteeism. This finding suggests that while more studies have focused on the costs of absenteeism, presenteeism may present a larger problem in terms of dollars lost. Additional work is needed to clarify the relative magnitudes of these costs.

Pronk et $\mathrm{al}^{15}$ include outcome variables that measure quality of work performed as well as workplace inter-personal relationships. The only statistically significant presenteeism relationship found with obesity was on inter-personal relationships. However, the study includes physical activity and cardiorespiratory fitness measures as explanatory variables, which are likely to mediate effects of obesity, as shown in other studies.

\section{Disability}

In addition to absenteeism and presenteeism, obesity may lead to an increase in disability payments and disability insurance premiums. Such an increase could reflect a loss in productivity beyond what is captured in absenteeism data if recipients are unable to hold a job altogether. Additionally, an increase in the disability rolls represents higher fiscal costs to the federal government.

Burkhauser and Cawley ${ }^{32}$ study the effects of obesity both on self-reported work impairment and Social Security Disability Insurance. The authors do parallel analyses in two datasets: the Panel Survey of Income Dynamics and the NLSY. Several econometric specifications are used: two OLS models, one linear and one nonlinear, and an IV model using a sibling's or biological child's weight as an instrument for respondent weight. Potential bias introduced by self-reporting of weight is corrected for. Control variables include education, marital status, race, gender, and children in a household. Results are robust to specification changes for receipt of disability income. For men in the NLSY, being obese raises the probability of receiving disability income by 6.92 percentage points, which is equivalent to losing 15.9 years of education. For women, the increased probability of receiving disability is 5.64 percentage points, which is 
the equivalent of losing 16.7 years of education. Thus, even after controlling for a list of covariates and endogeneity of weight, the authors find a significant and large effect of obesity on receipt of disability insurance. More research is needed to determine the productivity loss associated with this correlation: to what extent does being on disability decrease employment among recipients?

\section{Premature mortality}

Another form of productivity loss associated with obesity is premature mortality or reduction in QALYs. Several studies have found a connection between obesity and mortality. ${ }^{30}$ A recent study by Fontaine et $\mathrm{al}^{33}$ measures years of life lost due to obesity, controlling for demographic and other factors affecting morbidity. The authors determine the distribution of individuals across BMI categories, as well as life expectancy at each age between 18 and 85 years in each BMI category, and calculate years of life lost (YLL) in each category relative to a reference BMI of 24 (the high end of the normal-weight range). In general, YLLs follows a J- or U- shaped distribution across BMI categories. The largest effect of obesity on morbidity was for white men: a white male aged 20 years with a BMI over 45 could be expected to have 13 YLLs, the equivalent of a $22 \%$ reduction in remaining life years. Effects for black men and women were much smaller.

Groessel et $\mathrm{al}^{34}$ consider the effects of BMI on quality of life in a longitudinal cohort study of older individuals (mean age 72 years). The authors measure QALYs with a quality of well-being (QWB) scale that rates symptoms and functionality. After controlling for age, sex, smoking and exercise, they compare statistical differences in mean QWB scores between obese and nonobese BMI groups. Obese individuals were found to have 0.046 lower QWB scores on average, which translates into 2.93 million QALYs lost at the national level in the US. This result is equivalent to one QALY lost for every 20 people who live one year with obesity. Both premature mortality and lost QALYs represent important economic impacts of obesity. Further research would be needed to monetize this impact for comparison with other costs.

\section{Health insurance}

Though few studies have considered it, another potential economic cost of obesity is a health insurance market externality. Several studies have estimated the portion of health care expenditure on obesity that is paid for by public insurance. ${ }^{35}$ However, in addition to the extra medical costs, Bhattacharya and Sood $^{35}$ argue that pooled insurance may actually cause a moral hazard that incentivizes overweight and obesity by transferring the economic costs away from the obese to the larger insurance pool. Such a problem could induce additional costs of obesity via welfare loss. The authors note that even if an individual does not consciously choose to consume more calories or exercise less, pooled insurance reduces the price of obesity, and obesity has been shown to be somewhat responsive to price signals (eg, food prices).

In order to determine whether there is a welfare loss caused by this externality, the authors consider two models of health insurance: one in which there is complete, employer-provided, pooled insurance, and another in which premiums are risk adjusted. The difference in utility under the optimal solution in each model is then measured to find welfare loss. After calibrating the model using data from the MEPS, the authors find that there is in fact a welfare loss under pooled insurance. The loss is proportional to the product of the difference in medical expenditures between the obese and nonobese, and the elasticity of body weight to the insurance subsidy provided by pooled insurance. The size of the welfare loss due to the obesity externality in the US is estimated at $\$ 150$ per capita.

\section{Total indirect costs}

Several papers have estimated the total economic cost of obesity, differentiating only between direct and indirect costs. Direct costs include those discussed in the first section of this paper, while indirect costs focus on premature mortality, higher disability insurance premiums, and labor market productivity. Notably, the papers reviewed here provide a reasonably wide range of estimates for the total indirect costs of obesity. However, direct comparison of results across studies is difficult due to such factors as the date of measurement, representativeness of the sample, and scope of measurement. Differences in findings may be due to a confluence of factors in the design of the studies, rather than simply differences in econometric specifications or data sources.

For example, Thompson et $\mathrm{al}^{36}$ look at the total cost of obesity to US businesses, differentiating between health insurance expenditures and paid sick leave, life insurance, and disability insurance. The study is based on data from the National Health Interview Survey, and BLS and other data representing expenditures of all private-sector US firms. Using age- and sex-specific obesity-attributable expenditures, the authors estimate that total nonmedical costs of obesity among US businesses were $\$ 5$ billion in 1994. Of that, $\$ 2.4$ billion was spent on paid sick leave, $\$ 1.8$ billion on life insurance, and $\$ 0.8$ billion on disability insurance. The health insurance-related costs of obesity were estimated to be $\$ 7.7$ billion. 
On the other hand, a study by Lightwood et $\mathrm{al}^{22}$ looks at current and future costs of adolescent overweight. In this case, the indirect costs include work loss due to sick and disability leave, as well as long-term disability, early retirement, and premature mortality. Using employee compensation data, along with information on clinical events related to obesity, diabetes, and CHD, the authors estimate indirect costs due to work absence or reduced work. They project cumulative costs from 2020 to 2050 by making assumptions about productivity growth and trends in obesity. Likewise, the cost of premature mortality is measured using the probability of employment for a given age and gender, varying by BMI, and is projected forward from 2020 to 2050 . The cumulative, discounted costs of obesity (including costs due to diabetes and $\mathrm{CHD}$ ) over that period are estimated at $\$ 254$ billion, $\$ 208$ billion of which is due to indirect costs.

These examples illustrate the substantial differences found across studies that provide disaggregated estimates for direct and indirect costs of obesity, as well as absenteeism and other sub-categories of indirect costs. The relative significance of indirect to direct costs varies between $65 \%$ and $88 \%$ in these two examples, and in the studies discussed above, absenteeism is reported to range from as low as $20 \%$ of total indirect costs to as high as $50 \%$. Future research could effectively parse the source of the differences across studies, making results more comparable in order to get a better sense of the total and relative magnitudes of obesity's likely economic impacts.

\section{Transportation costs}

In addition to its impact on medical spending and productivity, obesity may affect transportation costs. Increases in body weight among Americans mean that more fuel and, potentially, larger vehicles are needed to transport the same number of commuters and travelers each year. This produces a direct cost (in the form of greater spending on fuel), as well as potential indirect costs in the form of greater greenhouse gas emissions. A number of recent papers assess these impacts.

Dannenberg et $\mathrm{al}^{37}$ provide a direct estimate of the one-year fuel costs for the passenger airline sector that are associated with increased levels of obesity in US adults from 1990 to 2000. Using US Dept of Transportation figures for the fuel needed to transport a given weight of cargo by air, and data on the number of passenger-miles flown, they calculate that weight gain during the 1990s required approximately 350 million extra gal of jet fuel in the year 2000. At a prevailing price of $\$ 0.79 / \mathrm{gal}$, they calculate the extra airline fuel cost due to higher obesity to be approximately \$275 million in the year 2000 alone.

Jacobson and $\mathrm{King}^{38}$ use a mathematical model to estimate the additional annual fuel consumption by noncommercial passenger highway travel in the US that is associated with overweight and obesity to be approximately one billion gal. At current US prevailing prices, ${ }^{39}$ this represents a cost of $\$ 2.7$ billion a year. Jacobson and $\mathrm{McLay}{ }^{40}$ provide a similar annual estimate of the fuel-use impact of obesity in the US. They also estimate that approximately 39 million additional gal of fuel (worth $\$ 105$ million at current prices) are needed annually in this sector for each $1 \mathrm{lb}$ of additional average passenger weight. $\mathrm{Li}$ et $\mathrm{al}^{41}$ also find evidence that a decrease in average miles per gal (MPG) in the US passenger vehicle fleet may be associated with increased obesity. Although cautious in drawing definitive conclusions, they use sales data from 1999-2005 to estimate that a 10 percentage point increase in overweight/obesity rates reduces average MPG of new vehicles sold by approximately $2.5 \%$.

Michaelowa and Dransfield ${ }^{42}$ conduct an Organization for Economic Co-operation and Development (OECD)-wide study of the impact of obesity on greenhouse gas emissions through three channels: higher fuel consumption needed to transport heavier people, greater food production needed to feed a population with higher caloric intake, and higher methane emissions resulting from the greater organic waste generated by a heavier population. They estimate that reduction of average weight by $5 \mathrm{~kg}$ across the OECD could reduce $\mathrm{CO}_{2}$ emissions from the transportation sector by approximately 10 million $\mathrm{T}$ annually. Reduced consumption of energy-rich foods to 1990s levels is estimated to lead to savings of approximately 102 million T. No economic cost estimate is assigned to greenhouse gas emissions due to obesity.

\section{Human capital accumulation}

Effects of obesity and overweight on educational attainmentboth quantity and quality of schooling - also represent a potential economic impact, one that may become increasingly significant as rates of childhood and adolescent obesity climb. We review four studies in this section that consider the relationship between obesity and human capital accumulation.

Gortmaker et $\mathrm{al}^{43}$ include a broad set of outcome variables, following a cohort from the NLSY (16 to 24 year-olds) for seven years to determine whether membership in a high-BMI category leads to lower income or educational attainment, more health conditions, or lower self-esteem. Baseline characteristics were measured in 1979, with obesity defined as a BMI over the 95th percentile of the distribution in NHANES, 
given an individual's age and sex. Self-esteem and intelligence were also measured at baseline. Overall correlations between obesity and the outcome variables were statistically significant and in the expected directions. Once controls were added for baseline characteristics and demographic variables, only select correlations remained significant. Women who had been obese in the baseline survey had significantly fewer years of school completed ( 0.3 year on average). Likewise, they were less likely to be married, had lower household incomes, and higher rates of poverty. For men, the only statistically significant correlation was for marital status.

Instead of measuring cross-sectional differences in educational attainment as done by Gortmaker et $\mathrm{al}^{43}$ Kaestner et $\mathrm{al}^{44}$ look at an NLSY cohort to study the effects of obesity on grade progression and drop-out rates. To do this, the authors measure the change in the highest grade completed by an individual between ages $t-1$ and $t$. The study includes respondents aged 14 to 17 , and models the effects of obesity on grade progression separately for each age, using three different models. The first model measures the overall correlation, the second controls for a list of covariates including family structure and educational attainment, respondent health, smoking status, alcohol consumption, and region, and the third model instruments weight at age $t-1$ with weight in the previous year.

The results are mostly not statistically significant, though when they are, the effects are quite large. Fifteen-year-old males in the 90th percentile or above for BMI are 3.3 percentage points more likely to drop out in the following year than their counterparts in the second and third BMI quartiles; 16-year old females in the 90th percentile or above are 12 percentage points less likely to complete a higher grade in the IV model. It is possible that the samples used in this study were simply too small to allow for enough statistical power to pick up any smaller effects of obesity.

In addition to educational attainment and grade progression, obesity has also been shown to correlate with school attendance. The impact of school attendance on human capital and productivity is likely to operate through its effect on educational attainment; attendance could also affect productivity via associated parental work absenteeism. Geier et $\mathrm{al}^{45}$ study the effects of overweight and obesity on school attendance, and find that days missed from school are significantly higher for obese children than their normal-weight counterparts. The authors sample just over 1,000 students in nine inner-city Philadelphia schools; they measure their weight and height during a school year, and record their absences. Demographic data on age, race, and sex are included, in addition to the fraction of a school body on free or reduced school lunch. Controlling for covariates, the authors find that while normal-weight children missed between 10.1 and 10.5 days of school over the year on average, obese children missed between 11.7 and 12.2; the difference in means is statistically significant.

Finally, measures of academic performance can provide an estimate of the relationship between obesity and the quality of education, potentially affecting human capital accumulation independently of educational attainment. Sabia ${ }^{46}$ measures the effect of adolescent obesity on grade point average (GPA). The author uses data from the NLSY and includes respondents aged 14 to 17 who were not pregnant at the time of the survey. GPA is measured by combining self-reported grades received in English/language arts and Math. Obesity is defined using BMI, weight controlling for height, and self-reported perception of obesity. Control variables included level of exercise, region, intelligence scores, parental involvement (eg, Parent-Teacher Association participation), family background, religion, sexual behavior, alcohol consumption, and age. The econometric specifications include one linear model, another with dummy variables for obesity, a third that uses a parent's self-reported weight as an instrument for the child's, and a fixed effects model. However, alternative specifications do not have large effects on the major results.

There is a consistent negative relationship between weight and GPA among females, though the magnitude is not very large. The point estimate for white females from the OLS regressions suggests that a $50 \%$ increase in BMI would lead to a $6.6 \%$ decline in GPA, and a $50 \mathrm{lb}$ weight gain would lead to a 0.17 point decline in GPA. Obese white females had a 0.182 point lower GPA on average relative to their nonobese counterparts. Sabia notes that while the size of the weight gains discussed is large, even a 0.2 point drop in GPA translates to a drop of eight percentiles. The results for nonwhite females are roughly similar in size and significance, with an even lower relative mean GPA among the obese group. Among males, the only significant correlation is for nonwhites: the individuals in the obese group had a 0.18 point lower mean GPA than those in the nonobese group.

The studies reviewed here provide statistical evidence of a potential link between obesity and the educational experience of students. Further research is needed in this area to clarify this relationship and identify potential mechanisms of action.

\section{Discussion}

The research on the economic impact of obesity reviewed above covers a broad range of potential costs. Table 1 summarizes some of the key costs identified. Substantial 


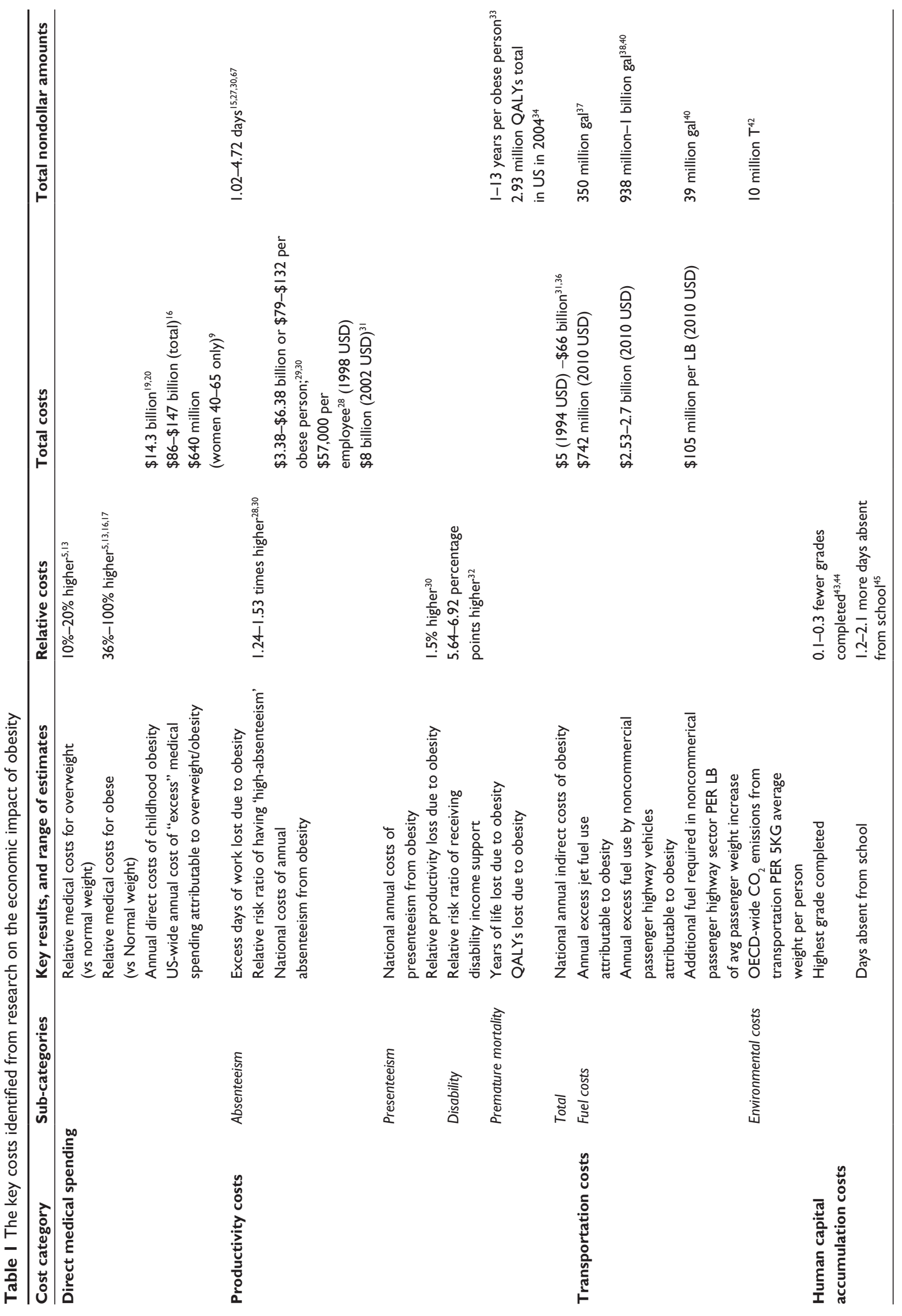


differences in methodology, scope, and data sources often make comparison between the studies reviewed difficult, and the depth of research varies widely across the four impact areas. In addition, this literature does not directly address policy choices for reducing obesity nor the likely aggregate economic impact associated with such changes. ${ }^{a}$ Nevertheless, several broad conclusions emerge from our review.

First, the direct medical costs associated with obesity are substantial. The literature reviewed in this paper gives a wide range of estimates for these costs, reflecting differences in methodology, definitions of weight categories, age groups studied, and data sources. However, all the studies reviewed find significant costs. Relative medical spending for the obese may be as much as 100\% higher than for healthy weight adults, and nationwide "excess" medical spending may amount to as much as $\$ 147$ billion annually for adults and $\$ 14.3$ billion annually for children. The estimates of direct costs reviewed here may generally be conservative they often rely on self-reported data (which tend to show a downward bias in BMI), and focus on a set of obesityrelated diseases more narrow than the full set identified in the medical literature. Medical costs appear to have increased dramatically over the last decade ${ }^{16}$ and may continue to grow with future increases in rates of overweight and obesity in US adults and children, perhaps substantially. ${ }^{47}$

Second, significant productivity costs are linked with obesity. Productivity effects may fall into at least four different categories (absenteeism, presenteeism, disability, and premature mortality). Several of the studies reviewed focus on only a subset of these effects, and there is extensive variation in cost estimates. These factors make comparisons between the studies, as well as between medical and productivity costs, difficult. However, total productivity costs are likely substantial, perhaps as high as $\$ 66$ billion annually for the US.

Third, important additional economic impacts of obesity can be found in the form of transportation costs and human capital accumulation costs. The studies reviewed in the final two sections of our paper suggest that these effects may be significant, but further work is needed to explore their full extent and assign consistent economic cost to them.

The overall economic impact of obesity in the US appears to be substantial. Although a comprehensive aggregation

\footnotetext{
${ }^{a}$ A rapidly growing body of research has arisen to evaluate potential costs and benefits of specific interventions. Integration of this research into a broader macroeconomic framework would allow careful assessment of the net economic impact associated with obesity reduction.
}

across the different categories of literature is an important goal for future research, simple addition of key effects identified in this review would suggest total annual economic costs associated with obesity in excess of \$215 billion. The magnitude of this impact, and the potential for high future impact identified by several studies, ${ }^{16,21,47}$ underscore the importance of the obesity epidemic as a focus for policy and a topic for future research.

\section{Disclosure}

The authors report no conflicts of interest in this work.

\section{References}

1. Flegal KM, Carroll MD, Ogden CL, et al. Prevalence and trends in US obesity among adults, 1999-2008. JAMA. 2010;303(3):235-241.

2. Huang TTK, Glass T. Transforming research strategies for understanding and preventing obesity. JAMA. 2008;300(15):1811-1813.

3. Hammond RA. Complex systems modeling for obesity research. Prev Chron Dis. 2009;6(3):A97.

4. Ogden CL, Carroll MD, Curtin LR, et al. Prevalence of overweight and obesity in the United States, 1999-2004. JAMA. 2006;295(13): 1549-1555.

5. Thompson D, Edelsberg J, Colditz GA, Bird AP, Oster G. Lifetime health and economic consequences of obesity. Arch Intern Med. 1999; 159(18):2177-2183.

6. Rimm EB, Stampfer MJ, Giovannucci E, et al. Body size and fat distribution as predictors of coronary heart disease among middle-aged and older US men. Am J Epidemiol. 1995;141:1117-1127.

7. Colditz GA, Willett WC, Rotnitzky A, Manson JE. Weight gain as a risk factor for clinical diabetes mellitus in women. Ann Intern Med. 1995; 122:481-486.

8. Manson JE, Willett WC, Stampfer MJ, et al. Body weight and mortality among women. N Engl J Med. 1995;333:677-685.

9. Gorsky R, Pamuk E, Williamson D, Shaffer P, Koplan J. The 25-year health care costs of women who remain overweight after 40 years of age. Am J Prev Med. 1996;12:388-394.

10. Van Itallie TB. Health implications of overweight and obesity in the United States. Ann Intern Med. 1985;103:983-988.

11. Mokdad AH, Ford ES, Bowman BA, et al. Prevalence of obesity, diabetes, and obesity-related health risk factors. JAMA. 2001;289(1):76-79.

12. Wassertheil-Smoller $\mathrm{S}$. The case for nutritional intervention. In: Wassertheil-Smoller S, Alderman MH, Wylie-Rosette J, editors. Cardiovascular Health and Risk Management: The Role of Nutrition and Medication in Clinical Practice. Littleton, MA: PSG Publishing; 1989:16-45.

13. Thompson D, Brown JB, Nichols GA, Elmer PJ, Oster G. Body mass index and future healthcare costs: a retrospective cohort study. Obes Res. 2001;9(3):210-218.

14. WolfAM. Economic outcomes of the obese patient. Obes Res. 2002;10(1): 58S-62S.

15. Pronk NP, Goodman MJ, O’Connor PJ, Martinson BC. Relationship between modifiable health risks and short-term charges. JAMA. 1999; 282(23):2235-2239.

16. Finkelstein EA, Trogdon JG, Cohen JW, Dietz W. Annual medical spending attributable to obesity: payer- and service-specific estimates. Health Aff (Millwood). 2009;28(5):w822-w831.

17. Thorpe KE, Florence CS, Howard DH, Joski P. The impact of obesity on rising medical spending. Health Aff (Millwood). 2004; Suppl Web Exclusives:W4-w480.

18. Allison DB, Zannolli R, Narayan KM. The direct health care costs of obesity in the United States. Am J Public Health. 1999;89(8): 1194-1199. 
19. Cawley J. The economics of childhood obesity. Health Aff (Millwood). 2010;29(3):364-371.

20. Trasande L, Chatterjee S. The impact of obesity on health service utilization and costs in childhood. Obesity (Silver Spring). 2009; 17(9):1749-1754.

21. Serdula MK, Ivery D, Coates RJ, Freedman DS, Williamson DF, Byers T. Do obese children become obese adults? A review of the literature. Prev Med. 1993;22(2):167-177.

22. Lightwood J, Bibbins-Domingo K, Coxson P, Wang C, Williams L, Goldman L. Forecasting the future economic burden of current adolescent overweight: an estimate of the coronary heart disease policy model. Am J Public Health. 2009;99(12):2230-2237.

23. Bhattacharya B, Bundorf MK. The incidence of the healthcare costs of obesity. J Health Econ. 2009;28(3):649-658.

24. Dall TM, Zhang Y, Chen YJ, Quick WW, Yangh WG, Fogli J. The economic burden of diabetes. Health Aff (Millwood). 2010;29(2):297-303.

25. Burton WN, Chen CY, Schutz AM, Edington DW. The economic costs associated with body mass index in a workplace. J Occup Environ Med. 1998;40(9):786-792.

26. Frone MR. Obesity and absenteeism among US workers: do physical health and mental health explain the relation? JWorkplace Behav Health. 2007;22(4):65-79.

27. Tsai SP, Ahmed FS, Wendt JK, Bhojani F, Donnelly RP. The impact of obesity on illness absence and productivity in an industrial population of petrochemical workers. Ann Epidemiol. 2008;18(1):8-14.

28. Serxner SA, Gold DB, Bultman KK. The impact of behavioral health risks on worker absenteeism. J Occup Environ Med. 2001;43(4): 347-354.

29. Durden ED, Huse D, Ben-Joseph R, Chu BC. Economic costs of obesity to self-insured employers. J Occup Environ Med. 2008;50(9):991-997.

30. Trogdon JG, Finkelstein EA, Hylands T, Dellea PS, Kamal-Bahl. Indirect costs of obesity: a review of the current literature. Obes Rev. 2008;9(5):489-500.

31. Ricci JA, Chee E. Lost productive time associated with excess weight in the US workforce. J Occup Environ Med. 2005;47(12):1227-1234.

32. Burkhauser RV, Cawley J. Obesity, disability, and movement onto the disability insurance rolls. 2004 Oct. Available from: http://www.mrrc. isr.umich.edu/publications/Papers/pdf/wp089.pdf Accessed May 26, 2010.

33. Fontaine KR, Redden DT, Wang C. Years of life lost due to obesity. JAMA. 2010;289(2):187-193.
34. Groessel EJ, Kaplan RM, Barrett-Connor E, Ganiats TG. Body mass index and quality of well-being in a community of older adults. Am J Prev Med. 2004;26(2):126-129.

35. Bhattacharya J, Sood N. Health insurance and the obesity externality. 2006 Jan. Available from: http://www.randproject.org/pubs/working papers/2006/RAND_WR340.pdf Accessed May 26, 2010.

36. Thompson D, Edeslberg J, Kinsey KL, Oster G. Estimated economic costs of obesity to US business. Am J Health Promot. 1998;13(2): $120-27$.

37. Dannenberg A, Burton D, Jackson R. Economic and environmental costs of obesity: the impact on airlines. Am J Prevent Med. 2004; 27(3):264

38. Jacobson SH, King DM. Measuring the potential for automobile fuel savings in the US: the impact of obesity. Transport Res D-TR E. 2009; 14(1):6-13.

39. Energy Information Administration. US retail gasoline prices. 2010 May. Available from: http://www.eia.doe.gov/oil_gas/petroleum/ data_publications/wrgp/mogas_home_page.html. Accessed May 26, 2010.

40. Jacobson SH, McLay LA. The economic impact of obesity on automobile fuel consumption. Eng Econ. 2006;51:307-323.

41. Li S, Liu Y, Zhang J. 2009. Lost some, save some: obesity, automobile demand, and gasoline consumption in the United States. 2009 Jun 26. Available from: http://papers.ssrn.com/sol3/papers.cfm?abstract_ id=1425773 Accessed May 26, 2010.

42. Michaelowa A, Dransfield B. 2006. Greenhouse gas benefits of fighting obesity. Ecolog Econ. 2008;66(2-3):298-308.

43. Gortmaker SL, Must A, Perrin JM, Sobol AM, Dietz W. Social and economic consequences of overweight in adolescence and young adulthood. N Eng J Med. 1993;329(14):1008-1012.

44. Kaestner R, Grossman M, Yarnoff B. Effects of weight on adolescent educational attainment. 2009 May. Available from: http://www.nber. org/papers/w14994.pdf Accessed May 26, 2010.

45. Geier AB, Foster GD, Womble LG, et al. The relationship between relative weight and school attendance among elementary schoolchildren. Obesity (Silver Spring). 2007;15(8):2157-2161.

46. Sabia JJ. The effect of body weight on adolescent academic performance. Southern Econ J. 2007;73(4):871-900.

47. Wang Y, Beydoun MA, Liang L, Caballero B, Kumanyika SK. Will all Americans become overweight or obese? Estimating the progression and cost of the US obesity epidemic. Obesity (Silver Spring). 2008;16(10):2323-2330.

\section{Publish your work in this journal}

Diabetes, Metabolic Syndrome and Obesity: Targets and Therapy is an international, peer-reviewed open-access journal committed to the rapid publication of the latest laboratory and clinical findings in the fields of diabetes, metabolic syndrome and obesity research. Original research, review, case reports, hypothesis formation, expert opinion and commentaries are all considered for publication. The manuscript management system is completely online and includes a very quick and fair peer-review system, which is all easy to use. Visit http://www.dovepress.com/testimonials.php to read real quotes from published authors. 